\title{
Dissociative Electron Attachment of Singly Bonded [60]Fullerene Dimer Studied by Laser Flash Photolysis
}

\author{
Hongxia Luo, ${ }^{\dagger, £}$ Yasuyuki Araki, ${ }^{\dagger}$ Mamoru Fujitsuka,,${ }^{\dagger,}$ Osamu Ito, ${ }^{\dagger, *}$ \\ Fuyong Cheng, ${ }^{\ddagger}$ Yasujiro Murata, ${ }^{\ddagger}$ and Koichi Komatsu ${ }^{\ddagger}, *$
}

Institute of Multidisciplinary Research for Advanced Materials, Tohoku University,

Katahira, Aoba-ku, Sendai, 980-8577, Japan and Institute for Chemical Research, Kyoto

University, Uji, Kyoto 611-0011, Japan

\footnotetext{
* Author correspondence. E-mail: ito@tagen.tohoku.ac.jp

${ }^{\dagger}$ Tohoku University.

${ }^{\ddagger}$ Kyoto University.

$£$ Present address: Center for Molecular Sciences, Institute of Chemistry, Chinese Accademy Science, Bejing, 100080 China.

${ }^{\mathbb{I}}$ Present address: The Institute of Scientific and Industrial Research, Osaka University, Ibaraki, Osaka 567-0047, Japan.
} 


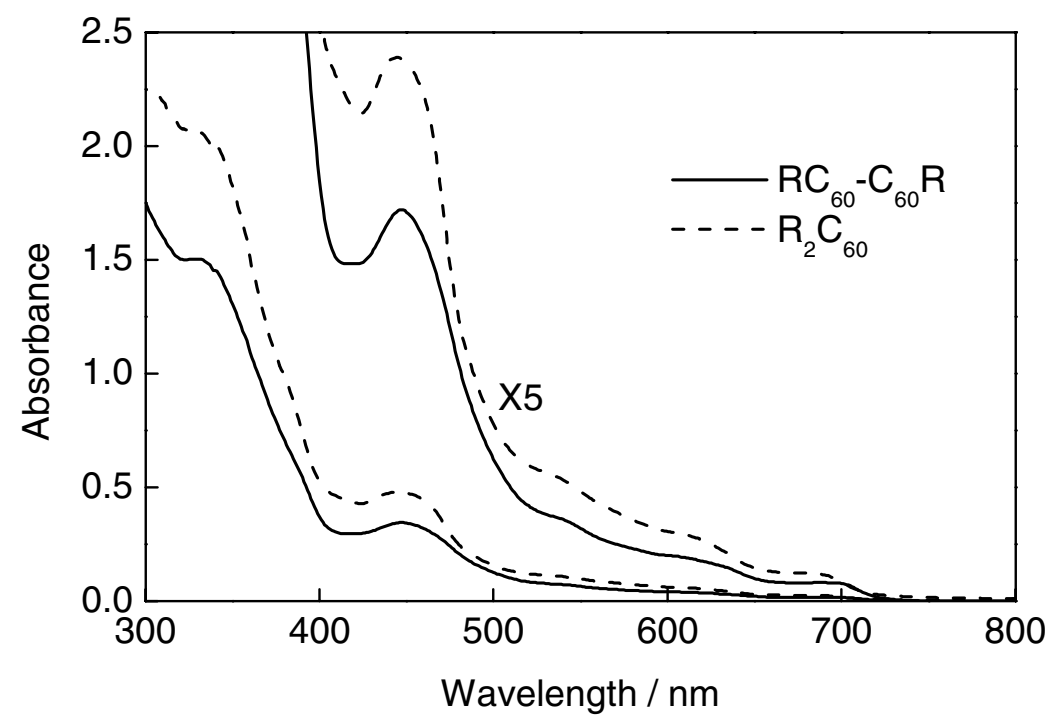

Figure S1. Steady-state absorption spectra of $\mathrm{RC}_{60}-\mathrm{C}_{60} \mathrm{R}(0.025 \mathrm{mM}$; solid line) and $\mathrm{R}_{2} \mathrm{C}_{60}(0.1 \mathrm{mM}$; broken line $)$ in toluene 


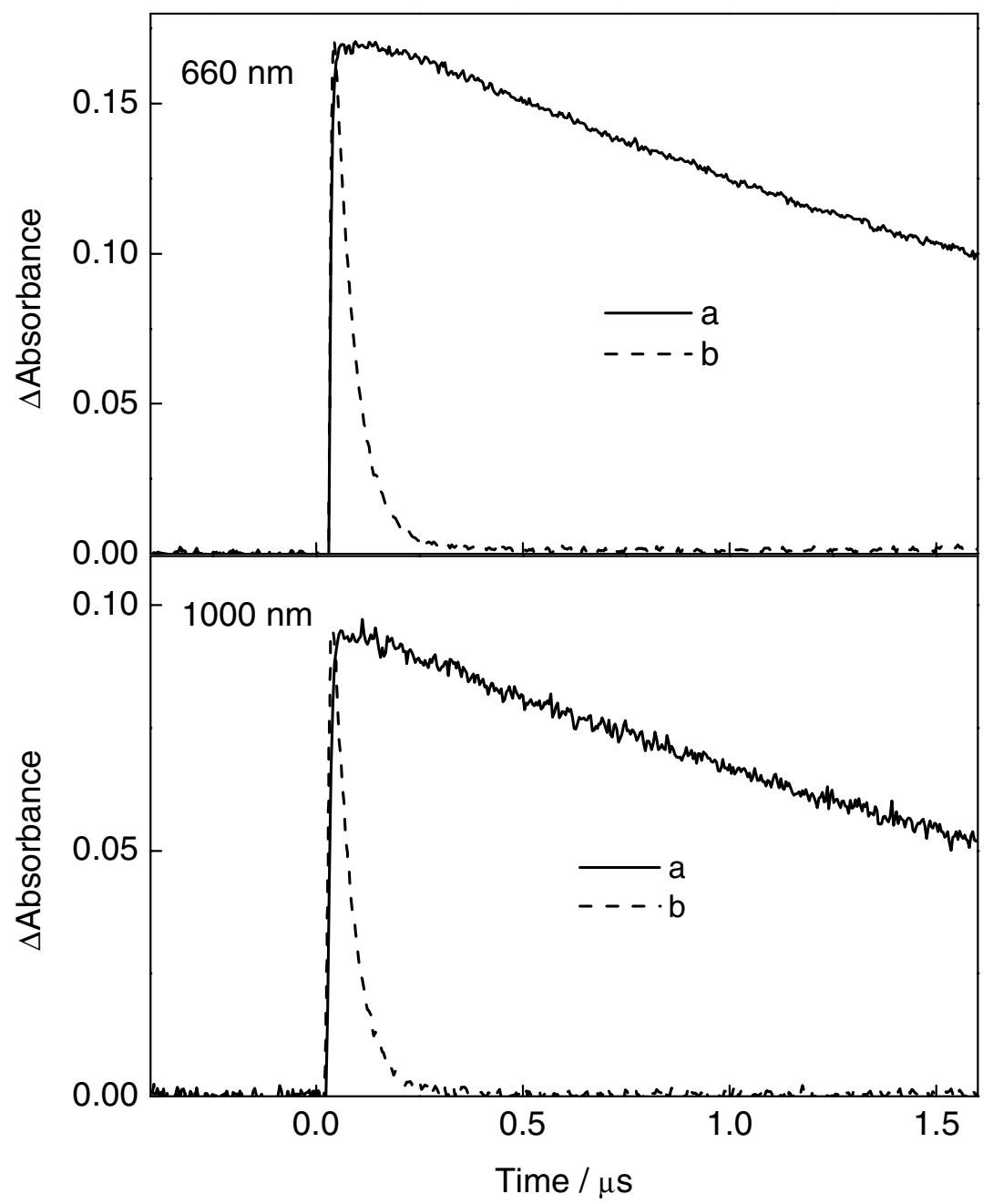

Figure S2. Temporal profiles of absorbance of $\mathrm{RC}_{60}-\mathrm{C}_{60} \mathrm{R}(0.1 \mathrm{mM})$ after $532 \mathrm{~nm}$ laser irradiation in (a) argon-saturated toluene and (b) oxygen-saturated toluene at 660 and $1000 \mathrm{~nm}$. 


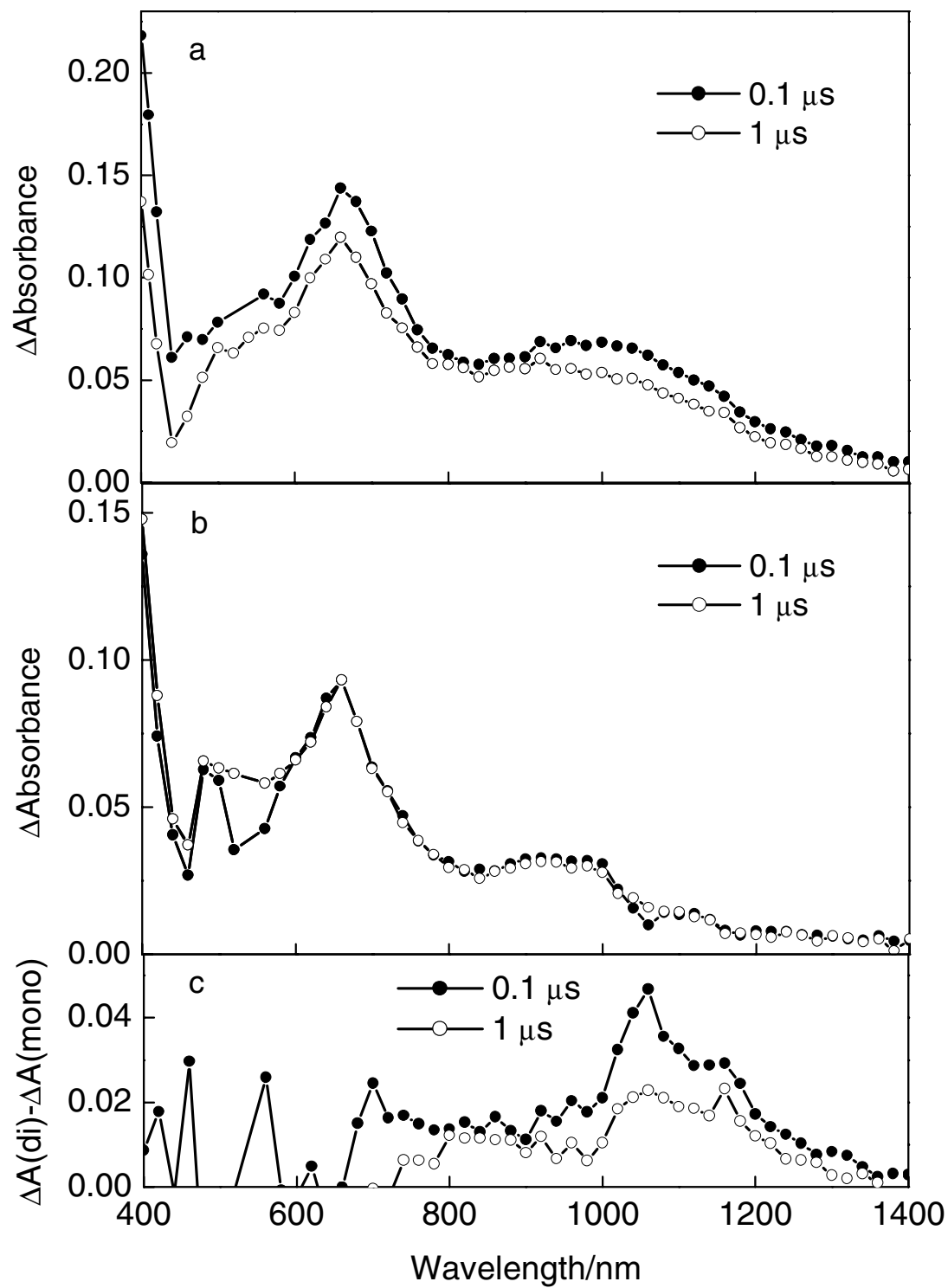

Figure S3. Nanosecond transient absorption spectra of (a) $\mathrm{RC}_{60}-\mathrm{C}_{60} \mathrm{R}(0.1 \mathrm{mM})$, (b) $\mathrm{R}_{2} \mathrm{C}_{60}(0.1 \mathrm{mM})$, and (c) difference spectrum $(\Delta \mathrm{A}($ dimer $)-\Delta \mathrm{A}($ monomer $))$ in toluene after $532 \mathrm{~nm}$ laser irradiation. 


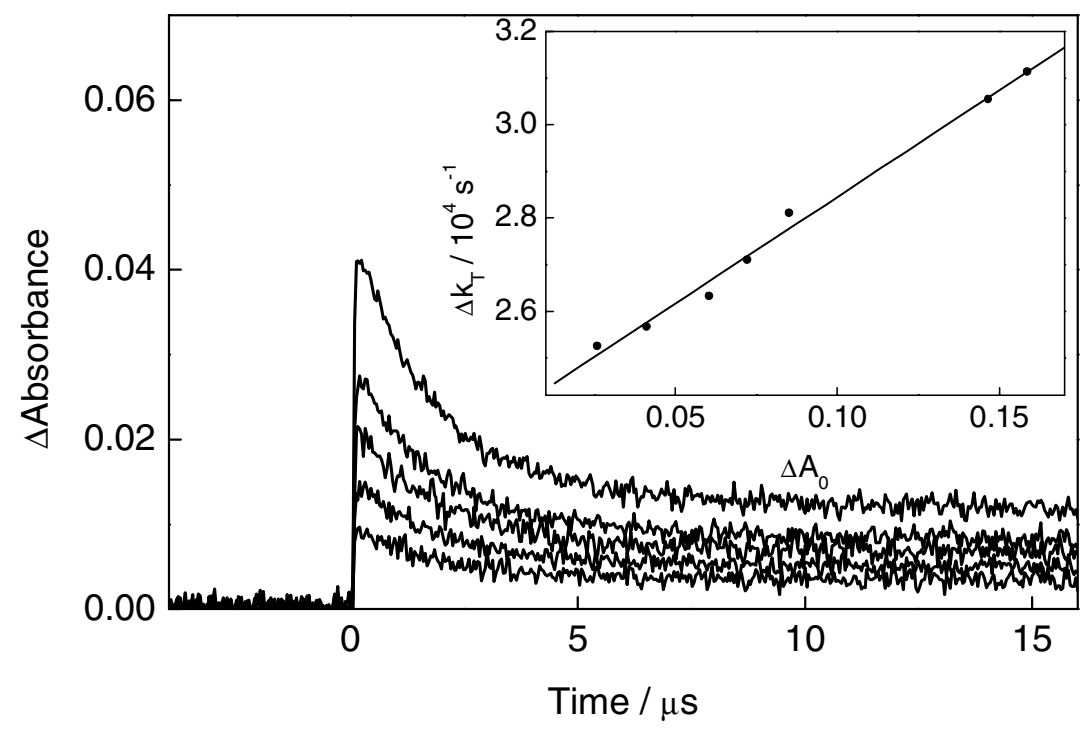

Figure S4. Transient absorption decay of $\mathrm{RC}_{60}-\mathrm{C}_{60} \mathrm{R}(0.1 \mathrm{mM})$ in toluene at $660 \mathrm{~nm}$ observed with varying laser power. Inset: Relation between $\Delta \mathrm{k}_{\mathrm{T}}$ and $\Delta \mathrm{A}_{0}$.

From the laser power dependence of the decay rates of ${ }^{3}\left(\mathrm{RC}_{60}-\mathrm{C}_{60} \mathrm{R}\right)^{*}$, the rate constant of the triplet-triplet annihilation process $\left(k_{\mathrm{TT}}\right)$ can be estimated using relation expressed as eq $\mathrm{S} 1$;

$$
(-\mathrm{d}[\ln (\Delta A)] / \mathrm{dt})_{\mathrm{t}=0}=\Delta k_{\mathrm{T}}=k^{0}+\left(2 k_{\mathrm{TT}} / \varepsilon_{\mathrm{T}}\right) \Delta \mathrm{A}_{0}
$$

where $\Delta \mathrm{A}_{0}$ refers to $\mathrm{T}-\mathrm{T}$ absorbance at $\mathrm{t}=0$ and $k^{0}$ to an intrinsic decay rate constant $\left(k_{\mathrm{T}}{ }^{0}\right)$ of ${ }^{3}\left(\mathrm{RC}_{60}-\mathrm{C}_{60} \mathrm{R}\right)^{*}$. Generation of $\mathrm{RC}_{60}{ }^{*}$ was considered to be too fast to affect the kinetics in microsecond region, while the coupling reaction of $\mathrm{RC}_{60}{ }^{\circ}$ was presumed to be extremely slower than the decay of ${ }^{3}\left(\mathrm{RC}_{60}-\mathrm{C}_{60} \mathrm{R}\right)^{*}$. As shown in the inset of Figure $\mathrm{S} 4$, the plot of $\Delta k_{\mathrm{T}}$ to $\Delta \mathrm{A}_{0}$ exhibits a linear relation. From the slope and the estimated molar extinction coefficient of the T-T absorption band $\left(\varepsilon_{\mathrm{T}}\right)$ for the $\mathrm{C}_{60}$ derivatives $\left(17000 \mathrm{M}^{-1} \mathrm{~cm}^{-1}\right.$, see text), ${ }^{\mathrm{R} 1}$ the $k_{\mathrm{TT}}$ value was evaluated. The $k^{0}$ value was evaluated from the intercept.

${ }^{R 1}$ Luo, C.; Fujitsuka, M.; Watanabe, A.; Ito, O.; Gan, L.; Huang, Y.; Hung, C. -H. J. Chem. Soc., Faraday Trans. 1998, 94, 527. 


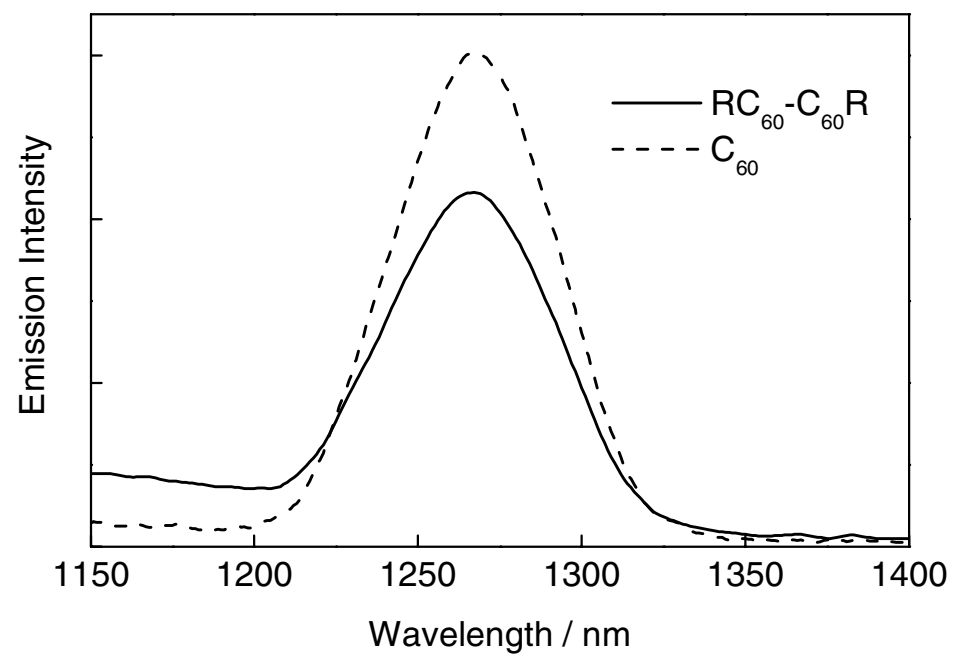

Figure S5. Emission spectra of singlet oxygen generated via ${ }^{3}\left(\mathrm{RC}_{60}-\mathrm{C}_{60} \mathrm{R}\right) *$ and ${ }^{3} \mathrm{C}_{60} *$ in $\mathrm{O}_{2}$-saturated toluene. Emission intensity of ${ }^{1} \mathrm{O}_{2} *$ was measured after the absorption intensities of the samples were matched at the excitation wavelength $(514 \mathrm{~nm})$.

The quantum yield for the singlet oxygen generation $\left(\Phi^{1}{ }_{\mathrm{O} 2}\right)$ can be expressed using the $\Phi_{\text {ISC }}$ value as eq $\mathrm{S} 2$;

$$
\Phi^{1}{ }_{\mathrm{O} 2}=\Phi_{\mathrm{ISC}} \times k_{\mathrm{ent}(\mathrm{O} 2)}\left[\mathrm{O}_{2}\right] /\left(k_{\mathrm{T}}+k_{\mathrm{ent}(\mathrm{O} 2)}\left[\mathrm{O}_{2}\right]\right)
$$

where $k_{\mathrm{T}}$ is the decay rate of the triplet absorption band in the absence of oxygen. The $\Phi^{1} \mathrm{O} 2$ value of $\mathrm{RC}_{60}-\mathrm{C}_{60} \mathrm{R}$ was estimated to be 0.74 by using $\mathrm{C}_{60}$ as a standand. ${ }^{\mathrm{R} 1}$ 


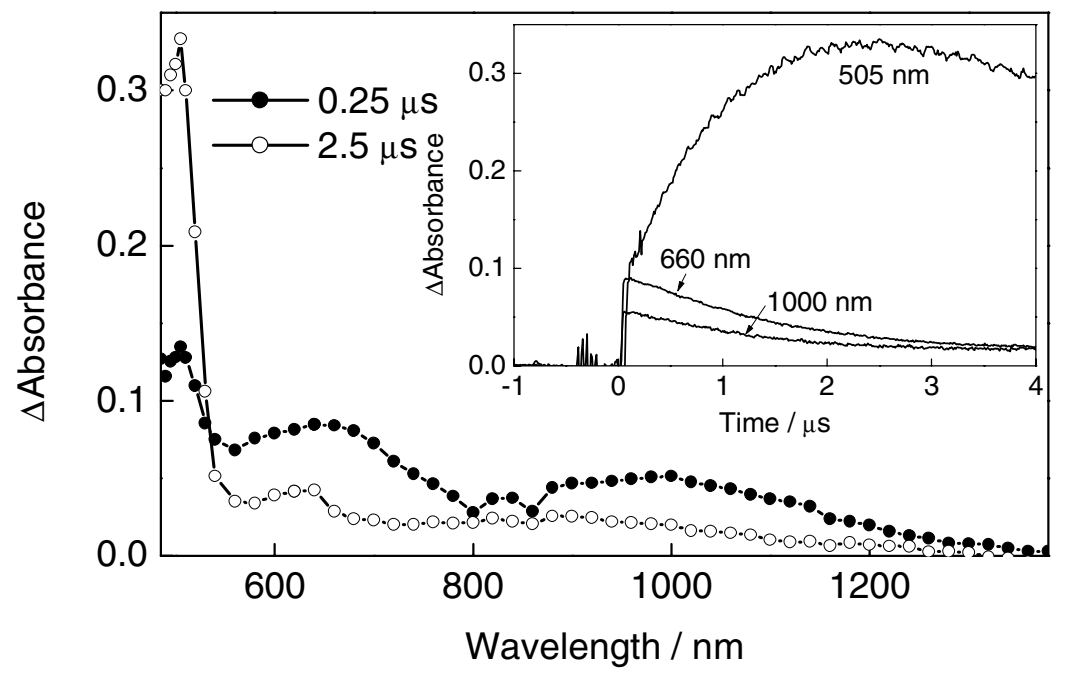

Figure S6. Nanosecond transient absorption spectra of $\mathrm{RC}_{60}-\mathrm{C}_{60} \mathrm{R}(0.05 \mathrm{mM})$ in the presence of $\beta$-carotene $(0.1 \mathrm{mM})$ in toluene after $532 \mathrm{~nm}$ laser irradiation. Inset: Absorption temporal profiles. 


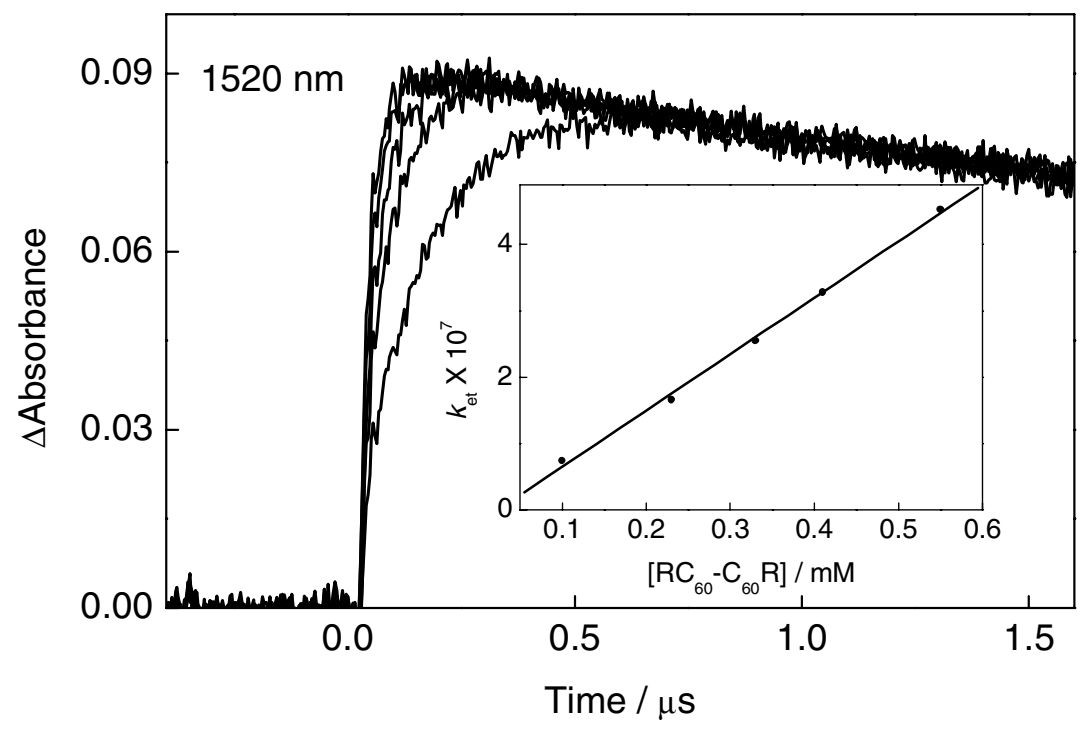

Figure S7. Concentration dependence of the time-profiles for the rise of $\mathrm{RC}_{60}-\mathrm{C}_{60} \mathrm{R}^{\circ-}$ in $\mathrm{RC}_{60}-\mathrm{C}_{60} \mathrm{R}$ - TMPD system in deaerated benzonitrile. Inset: Pseudo-first-order plot. 